\title{
Identidade profissional de professoras que ensinam matemática nos anos iniciais
}

\author{
Marjorie Samira Ferreira Bolognani \\ Adair Mendes Nacarato \\ Universidade São Francisco | Bragança Paulista
}

\section{Resumo}

Este texto discute as relações entre trabalho docente, formação, saberes e construção da identidade profissional. A pesquisa foi realizada com dez professoras que atuam nos anos iniciais do ensino fundamental e teve, como foco, o ensino de matemática. Os dados foram produzidos por entrevistas narrativas e grupo de discussão. Aquilo que as professoras lembram e narram trazem indícios de como os processos de formação vivenciados e o trabalho desenvolvido são por elas interpretados e ressignificados. Tais narrações, com a tomada de consciência, parecem ser determinantes à formação contínua delas, sinalizando o quanto as narrativas se constituem em práticas de autoformação.

Palavras-chave: trabalho docente. Identidade docente. Narrativas de vida.

\section{Professional identity for teachers of Mathematics in Elementary School}

\section{Abstract}

This text debates the relations among teaching work, formation, knowledge and the building of professional identity. The research has been carried out within ten teachers working in the first years of Elementary School, focusing on those who teach Mathematics. Data was produced through narrative interviews and a group of discussion. What teachers have reminded and brought up evidences how they interpret and attribute meaning to the processes of formation and the work developed. Such narratives, usually accompanied by the wake of self-awareness, seem to be determinant to the teachers' continuous formation, showing how much their narratives also constitute practices of selffformation. Keywords: Teaching work. Teachers' professional identity. Life narratives. 


\section{La identidad profesional de profesoras que enseñan matemáticas en la educación primaria}

\section{Resumen}

En este texto se discuten las relaciones entre trabajo docente, formación, saber y construcción de la identidad personal. La investigación se realizó con diez profesoras que trabajan en la educación primaria, y se dirigió específicamente a la enseñanza de las matemáticas. Las informaciones se obtuvieron a partir de entrevistas narrativas y grupos de discusión. Los recuerdos narrados por las profesoras muestran cómo interpretan los procesos de formación vividos y los trabajos desarrollados. Esas narraciones y la toma de conciencia son cruciales para su formación continua y señalan cómo las narrativas constituyen prácticas de auto-formación.

Palabras llave: Trabajo docente. Identidad docente. Narrativas de vida.

\section{Introdução}

Este texto refere-se ao recorte de uma pesquisa de mestrado, realizada pela primeira autora e orientada pela segunda e que teve como foco as trajetórias estudantis e profissionais de professoras que ensinam matemática nos anos iniciais do ensino fundamental. Para este texto, revisitamos os dados produzidos com o objetivo de analisar a construção identitária dessas professoras, a partir dos saberes que são apropriados ao longo do trabalho docente.

Ao discutirmos o trabalho docente fica evidente a complexidade que envolve o tema. Uma das características que permite tal afirmação é o fato de este trabalho acontecer com seres humanos, pois o professor se relaciona com membros de uma mesma sociedade, caráter coletivo da ação, ao mesmo tempo que se depara com a subjetividade do indivíduo, por suas singularidades e suas particularidades.

Nessa interação com o outro - os colegas de profissão, os alunos, os pais, a comunidade em torno da escola e as instituições externas - ocorrem interações que constroem e modificam a identidade do professor. Tardif e Lessard (2005, p. 28), ao citarem Marx, destacam que "[...] o processo do trabalho transforma dialeticamente não apenas o objeto, mas igualmente 0 trabalhador, bem como suas condições de trabalho". 
Podemos afirmar que a identidade docente é definida pelas e nas reflexões e nas interações do trabalho, nas relações e negociações humanas que ocorrem no cotidiano escolar e fora dele. Na análise do trabalho docente, não se pode ignorar a ambiguidade do papel do professor, como agente e como ator do processo do trabalho educacional. Nessa autoria, acreditamos que os professores "[...] investem em seu local de trabalho, que pensam, dão sentido e significado aos seus atos, e vivenciam sua unção como uma experiência pessoal, construindo conhecimentos e uma cultura própria da profissão [...]" (TARDIF; LESSARD, 2005, p. 38), e transformam em instrumentos os artefatos materiais e simbólicos construídos na profissão ao longo do tempo (MACHADO, 2007).

Entre as múltiplas possibilidades de análise do trabalho docente, apoiamo-nos nas perspectivas histórico-cultural e sociológica. Uma das abordagens metodológicas que tem possibilitado a tomada de consciência dos professores sobre sua atividade profissional é o uso de narrativas e, neste caso em particular, as narrativas de vida.

Partimos dos pressupostos de que o tempo de vida na profissão, o repertório de saberes construído ao longo da prática e a experiência profissional, marcada pelas interações humanas, modelam e constroem a identidade do professor. Com base nas vozes das professoras participantes da pesquisa, buscamos, neste artigo, identificar as evidências de construção e transformação da identidade profissional nas narrativas produzidas por elas, tendo como foco o ensino de matemática nos anos iniciais.

texto está organizado em cinco seções. Inicialmente, apresentamos em duas seções as dimensões teóricas que fundamentaram a pesquisa: o estudo das narrativas de vida, a constituição de um repertório de saberes para o exercício da profissão docente e a consequente construção da identidade. Em seguida, apresentamos o contexto da pesquisa, seguido da análise das narrativas buscando evidências de como foi a construção identitária dessas professoras e a produção de novos sentidos para a profissão, a partir do ato de narrar. Por fim, fazemos algumas amarras das análises realizadas. 


\section{O estudo das narrativas de vida e a formação docente}

Como a documentação da pesquisa foi construída com base em narrativas das professoras, entendemos também ser preciso discutir aqui as concepções de narrativas de vida. Tais concepções também foram dialogadas com os colegas participantes do grupo Histórias de Formação de Professores que ensinam Matemática (HIFOPEM).

Mas o que podemos considerar como narrativa ou história de vida? A singularidade de uma história de vida pode atender à pesquisa, ou melhor, pode tornar-se conhecimento científico? Essa questão fazemos com Ferrarotti (2010), para quem as histórias de vida vêm ganhando reconhecimento e legitimidade como conhecimento científico, rompendo com paradigmas positivistas que defendiam o distanciamento do sujeito com objeto de pesquisa. Reconhecer que as narrativas de vida se constituem em fonte de produção de dados para as pesquisas em educação é admitir que não é possível separar corpo e mente, sujeito e objeto de pesquisa; é admitir que a subjetividade é inerente à pesquisa qualitativa.

Para as nossas reflexões sobre narrativa de vida, dialogamos com

78 Bertaux (2010) que afirma ser essa qualquer episódio de vivência narrado pelo sujeito a outra pessoa. Para o autor, se algo foi contado, "[...] a produção discursiva do sujeito tomou a forma narrativa [...]" (BERTAUX, 2010, p. 47, grifos do autor). $\bigcirc$ discurso produzido inclui, além da narrativa, outras formas - como a descrição, a explicação e a avaliação - para a produção de significados.

A respeito da singularidade das narrativas, Ferrarotti formula que somos sínteses

[...] individualizada e ativa de uma sociedade [...] se nós somos, se todo o indivíduo é a reapropriação singular do universal social e histórico que o rodeia, podemos conhecer o social a partir da especificidade irredutível de uma práxis individual (FERRAROTTI, 2010 , p. 45, grifos do autor).

Para superar as singularidades existentes nos acontecimentos vivenciados, Bertaux (2010, p. 48) propõe que se relacionem vários relatos de vivência de uma mesma "situação social", alcançando, assim, "[...] uma representação sociológica dos componentes sociais (coletivos) da situação". 
Ao contar nossa história de vida, construída pela memória narrada, contamos nossa própria história e também a de outros (PRADO; ROSA; SADALLA; GERALDI, 2008, p. 73). Numa perspectiva bakhthiniana, os autores afirmam: "[...] a alteridade é constitutiva do sujeito. Somos diversos, singulares, polifônicos: sujeitos de dispersão. De qualquer forma, após nos termos identificado com o outro, devemos voltar a nós mesmos, recuperar o próprio lugar."

Quanto aos sujeitos que narram, como teoriza Bertaux (2010, p. 29), é atribuída ênfase ao que lhes é exterior, ou seja, suas vivências produzidas no contexto social. A narrativa de vida torna-se "[...] um instrumento importante de extração dos saberes práticos, com a condição de orientar para a descrição das experiências vividas pessoalmente e dos contextos nos quais elas se inscrevem". Além disso, o material biográfico pode permitir a seus autores, mediante o desejo desses e o esforço de reflexividade, pensar em várias questões. Josso (2006) nos apresenta alguns questionamentos e os chama de macroquestões:

[...] sobre o que eu me apoio para pensar ser aquele ou aquela que penso ser e quero me tornar-me? Como me configurei como sou? E como me transformei?

Sobre o que me baseio para pensar o que penso? De onde me vêm às ideias que acredito serem minhas?

Sobre o que me apoio para dizer o que digo la escolha das temáticas, abordadas nos relatos) da maneira como enuncio (de onde vem o meu linguajar e o meu vocabulário). De onde vem minha inspiração, minhas aspirações e meus desejos? UOSSO, 2006, p. 26).

Essas questões, pensadas, com base nas próprias histórias de escolarização são fecundas para a formação, "[...] porque se ancora nos recursos experienciais engendrados nas marcas acumuladas das experiências construídas e de mudanças identitárias vividas pelos sujeitos em processo de formação e desenvolvimento" (SOUZA, 2006, p. 136).

Partilhamos da ideia de formação concebida por Dominicé (2010a, p. 222 e 201 ) quando afirma que, para ser considerado como lugar de construções particulares, "[...] o tempo de formação contínua necessita que a contribuição educativa se dirija ao processo de formação". Tanto nos casos de formação profissional como nos casos de formação durante o trabalho na escola, a formação do adulto professor precisa passar por sua história de 
vida, pois sua história de vida é "[...] espaço da educação [...]" (DOMINICÉ, $2010 a$, p. 2011.

Os momentos de singularidades considerados nas narrativas de vida nos permitem entender como cada um se tornou o que é. Além disso, "[...] as narrativas constituem documentos históricos sobre as concepções de educação que prevalecem em certos momentos ou em determinados meios [... $]^{\prime \prime}$ (DOMINICE, 2010a, p. 219).

Com isso, os textos biográficos podem tornar-se um local de "[...] apropriação de contribuições educativas mais especializadas ou articuladas sobre conhecimentos particulares [...]", pois "[...] põem-nos na pista de processos de formação [...]" (DOMINICÉ, 2010a, p. 214) ao mesmo tempo que permitem a reflexão das tendências e das práticas da educação.

Com esse foco, a entrevista narrativa apresenta-se como um método de produzir dados biográficos (JOVCHELOVITCH; BAUER, 2005). Sobre a compreensão que se faz das histórias narradas, Souza (2006, p. 137) afirma que esse entendimento desvela e/ou reconstrói para "[...] processos históricos e socioculturais vividos pelos sujeitos em diferentes contextos".

Sobre as experiências individuais, Nacarato e Passeggi (2012, p. 213) afirmam que assumir as narrativas de formação "[...] práticas formativas traz para o âmbito das pesquisas em educação a atribuição de valor de conhecimento à subjetividade". Acreditamos que os sujeitos se formam em uma rede de poder e que as escolhas não são aleatórias. Narrar o próprio cotidiano e a formação subsidiará ao educador que almeje questionar as relações de poder que emanam de seu próprio discurso e de sua prática.

\section{A constituição de um repertório de saberes para o exercício da profissão docente e a construção da identidade profissional}

Que saberes são necessários aos professores, visto que não estamos falando em transmitir conhecimento? $\bigcirc$ que faz um professor para mobilizar um sujeito para o processo de humanização, socialização e subjetivação nas aulas de matemática? Como esses saberes são construídos?

Compreender os saberes docentes é compreender sua evolução, sua transformação ao longo de sua história, das histórias de vida e da carreira 
"[...] que remetem a várias camadas de socialização e de recomeços" (TARDIF, 2002, p. 106).

Para Tardif, o saber do professor é plural e temporal, construído de vários saberes, e implica

[...] um processo de aprendizagem e de formação; e, quanto mais desenvolvido, formalizado e sistematizado é um saber, como acontece com as ciências e os saberes contemporâneos, mais longo e complexo se torna o processo de aprendizagem, o qual, por sua vez, exige uma formalização e uma sistematização adequada (TARDIF, 2002, p. 35).

Para esse autor, os diferentes saberes podem ser nomeados como: 1) os saberes disciplinares, que "[...] correspondem aos diversos campos do conhecimento [...]" (TARDIF, 2002, p. 38) oferecidos nas universidades; 2) os saberes curriculares, os quais os professores devem aplicar nos programas escolares, nos objetivos, nos conteúdos, nos métodos; 3) os saberes profissionais, transmitidos na formação de professores, incluindo a prática docente, objeto de saber das ciências da educação e da pedagogia; e 4) os saberes experienciais, referentes ao trabalho docente no meio, ou seja, construído na prática do professor. Além disso, há, também, os saberes pedagógicos do professor, ou seja, os saberes que dizem respeito ao modo de ensinar os diferentes conteúdos.

Entre os múltiplos saberes, os experienciais são centrais, como modeladores dos demais. São saberes práticos e não da prática, saberes que criam a cultura do professor em seu trabalho diário, a partir de "[...] improvisação e habilidade pessoal [...]" e enfrentamentos de "[...] situações mais ou menos transitórias e variáveis [...]" (TARDIF, 2002, p. 49).

No trabalho cotidiano, o professor interage com os alunos, os pais e os responsáveis, com a comunidade, com os pares, com outros gestores, enfim, interage com outras pessoas. Essas interações, como afirma Tardif (2002, p. 50), não exigem um saber sobre uma prática e sim a "[...] capacidade de se comportarem como sujeitos, como atores".

Há de se considerar que os saberes experienciais perpassam pelos demais saberes: disciplinares; pedagógicos do conteúdo; curriculares; profissionais; além daqueles que, construídos ao longo de sua história de vida, moldam sua identidade, com "[...] consequências não intencionais $[\ldots]$ " 
(TARDIF, 2002, p. 214), e que inclui sua formação desde a entrada na escola como aluno. Para esse autor, o tempo de vida profissional modela a identidade do professor; por isso, além de plural, o saber do professor é temporal. A importância desses saberes está na sua objetivação, pois - ao sistematizar os saberes construídos pelo professor na prática cotidiana, "[...] a fim de se transformarem num discurso da experiência capaz de informar ou de formar outros docentes e de fornecer uma resposta a seus problemas [...]" - o docente se torna um formador (TARDIF, 2002, p. 52).

Neste sentido, fica difícil identificar exatamente as origens dos saberes nas narrativas produzidas pelas professoras colaboradoras da pesquisa. Saberes esses que servem ao ensino e à aprendizagem dos sujeitos envolvidos na educação escolar de uma forma não mecânica. Buscamos, nas narrativas das professoras, o que elas dizem a respeito das apropriações do que seja ensinar matemática, em outras palavras, os indícios de constituição de um repertório de saberes.

Assim, para compreender os saberes que as professoras vão se apropriando para o exercício da profissão docente, é preciso olhar para as suas trajetórias, a partir da formação, inicial e contínua, e de suas histórias de vida 82 e profissional. As narrativas das professoras evidenciam essas trajetórias e, ao refletir sobre elas, tomam consciência de sua identidade, produzindo sentidos a essa construção. Esses saberes são apropriados em suas práticas de ensinar e aprender para ensinar; elas constituem a base para a construção da identidade do trabalhador professor (TARDIF; RAYMOND, 2000), uma identidade social.

Cunha, Fernandes, Mota e Nogueira (2007) entendem que a construção de identidade profissional se dá pela seleção e pelos acúmulos numerosos de identificações que a pessoa faz ao longo da vida.

Percebemos, ainda, que, nas narrativas, ao evocar as preferências, as repulsas, os desafios, as conquistas, as posturas de ser professora, como afirmam Tardif e Raymond (2000, p. 216 , destaque dos autores), a temporalidade compõe a "[...] memorização de experiências educativas marcantes para a construção do Eu profissional e constitui o meio privilegiado de chegar a isso." Na narrativa, como explicam Nacarato e Passeggi (2012, p. 211 ), "[...] a professora dá sentido ao mundo vivido e à relação entre esse mundo 
e à interpretação que faz dele; entre a experiência humana e o ato de narrar; entre história individual e a história coletiva."

As narrativas das professoras evidenciam o quanto essas relações ocorridas na escola constroem as identidades, deixando-thes ora marcas negativas ora positivas que possibilitam superações de fracassos anteriores ou reiteram outros. Como afirmam Cunha, Fernandes, Mota e Nogueira

[...] a maneira como cada um se sente, diz-se professor, apropria-se do sentido de sua história pessoal e profissional é um processo que se refaz continuamente nos espaços escolares e em outros espaços para além deles, construindo uma identidade flexível e sensível às continuidades, descontinuidades, mudanças, inovações e rupturas presentes nesses espaços (CUNHA; FERNANDES; MOTA; NOGUEIRA, 2007, p. 154.)

No processo do trabalho, elas modificam sua identidade com características do que é ser professora, pois, como afirmam Tardif e Raymond (2000, p. 210$)$, "[...] uma boa parte de sua existência é caracterizada por sua atuação profissional".

Marcelo (2009, p. 118 ), ao debater sobre 14 "constantes" que identificam a identidade docente, conclui, entre outros fatores, que o conteúdo ensinado é capaz de construir a identidade desse profissional. Além disso, o conhecimento sobre o que se está ensinando influencia o que se ensina e "[...] influi no que e no como se ensina".

Quando as professoras, por exemplo, afirmam que reproduzem práticas que vivenciaram como alunas no início da carreira, refletem, durante a fala, o porquê de reproduzi-las e, ao fazerem isso, concluem: "sou assim porque comigo fizeram assim" e "funcionou comigo", ou seja, quando nos inserimos no mundo vamos dele se apropriando e dando também nossos contributos. Somos sujeitos históricos no e com o mundo.

A respeito da identidade pessoal e coletiva, Moita afirma:

[...] a identidade pessoal constitui também a apropriação subjetiva da identidade social - ou seja, a consciência que o sujeito tem de si mesmo é necessariamente marcada pelas suas categorias de pertença e pela sua situação em relação aos outros. De igual modo, as múltiplas dimensões da identidade social serão mais ou menos investidas e carregadas de sentido segundo a personalidade do sujeito (MOITA, 1995, p. 115). 
A reflexão sobre as trajetórias e as identidades profissionais, a formação acadêmica e continuada, as práticas, o aprender contínuo, a interação com os pares no contexto escolar, o convívio com os alunos e com um grupo de professoras dos anos iniciais que ensinam matemática, nos permitem analisar o "Ser" professora do ensino fundamental, a identidade social.

\section{O contexto da pesquisa}

Com foco nas trajetórias estudantis e profissionais de professoras que atuam nos anos iniciais do ensino fundamental, a partir daquilo que elas narram, a pesquisa foi realizada com dez professoras que atuam do $1^{\circ}$ ao $3^{\circ}$ ano do ensino fundamental em uma mesma escola da rede municipal de Jundiaí - São Paulo. A documentação da pesquisa foi constituída de: entrevistas narrativas textualizadas (JOVCHELOVITCH; BAUER, 2005); e devolvidas às professoras entrevistadas; transcrição das audiogravações de dois encontros do grupo de discussão (WELLER, 2006), os quais tomaram, como questões centrais, os temas considerados convergentes nas entrevistas narrativas; diário de campo da pesquisadora - primeira autora deste texto -, produzido após cada entrevista e cada encontro do grupo. Na apresentação dos excertos, utilizaremos EN para as entrevistas narrativas, seguida da data de sua realização; e GD para grupos de discussão, seguido de I ou II, visto que foram dois encontros do grupo, e a respectiva data.

Trata-se de uma escola com professores que se identificam com o local de trabalho, têm relações de afeto entre si e de confiança mútua, e dialogam com seus pares sobre suas tarefas. Essas características imprimem um tom diferencial ao grupo. Todas são professoras efetivas na rede de ensino, mas não na escola, uma vez que há, no corpo docente, professoras itinerantes, ou seja, são professoras efetivas na rede municipal, mas que não têm sede fixa; geralmente, substituem professores afastados por licença de longo período ou em outra função.

A equipe docente dessa escola desenvolve um trabalho colaborativo e coletivo na elaboração de suas atividades diárias, nos conflitos didáticos e nos sucessos de aprendizagem das crianças. Faz parte das condições de trabalho, nessa rede de ensino, o tempo da Hora de Estudo na escola, num total de três horas. Assim, a gestão da escola organizou o horário de forma que uma hora 
seria destinada aos estudos e às reflexões coletivas sobre temas e assuntos pedagógicos; outra, para atendimento aos responsáveis pelos alunos e para esclarecimentos de dúvidas pedagógicas com a coordenação; e a terceira hora era para que, juntos, com sua turma/ano de professores, pudessem planejar e socializar o trabalho pedagógico, ou seja, realizar o planejamento de aulas da semana seguinte.

Ainda com relação ao grupo da escola participante da pesquisa, observamos que os professores buscam, uns com os outros, forças para ultrapassar as barreiras pessoais que a vida thes coloca. $\bigcirc$ relacionamento com os demais funcionários é também harmonioso. A amizade acontece dentro e fora do espaço escolar.

Como eram 24 professores - o que dificultaria a viabilização da pesquisa, em um dia de Hora de Estudo - apresentamos o projeto, apenas, para as 10 professoras dos anos iniciais, $1^{\circ}$ ao $3^{\circ}$ ano do primeiro ciclo do ensino fundamental. Explicamos que a participação seria totalmente voluntária, por se tratar de um projeto independente da proposta da escola e que poderia requerer dedicação fora da jornada de trabalho. Após tirarmos as dúvidas apresentadas naquele momento, todas as 10 professoras, mulheres de 28 a 45 anos, disseram que gostariam de participar da pesquisa e assinaram o termo de livre consentimento, já aprovado pelo Comitê de Ética da Universidade. As professoras colaboradoras optaram por ser identificadas no trabalho com o pseudônimo de doces e a escola onde trabalham será por nós denominada de EMEB.

\section{A construção da identidade profissional de professoras que ensinam matemática}

Hoje eu vejo que eu posso trabalhar isso de forma diferente, hoje eu posso manusear essas figuras, eu posso comparar essas figuras. Naquela época, eu via um círculo, e do lado da escola tinha um carro, mas nunca ninguém me falou que a roda do carro era em forma de círculo (PAÇOCA, 2012).

Nesta seção, analisamos algumas evidências sobre as transformações ocorridas nos modos de serem professoras que ensinam matemática, a partir 
da prática docente. Nas entrevistas e nas reflexões no grupo de discussão, as professoras refletiram sobre suas trajetórias profissionais, o como ensinavam matemática no início da docência e as transformações, percebidas por elas, ocorridas em suas práticas.

excerto anterior, do depoimento de Paçoca (2012), aponta que as entrevistadas, quando falam das práticas que reproduziam, sinalizam uma mudança provocada pela reflexão que fizeram ao longo da carreira. Nessa mesma perspectiva, Laranjinha (GRUPO DE DISCUSSÃO II, 2011 ) reflete sobre seu processo de constante transformação - um processo de luta interna:

[...] eu batalho a cada dia, e eu presto atenção, eu luto contra mim mesma, porque foi a formação que eu tive, foi a escola que eu aprendi. Então, eu luto comigo, para que a minha prática mude a cada dia, e a cada novo ano, a cada nova turma, eu olhe e diga: 'Puxa, eu fiz diferente!' (LARANIINHA, 2011 ).

$\bigcirc$ fazer diferente pode apontar indícios de como ocorreu a ressignificação do que seja ser professora que ensina matemática. Nesse sentido, Merengue, Brigadeiro e Suspiro (GRUPO DE DISCUSSÃO II, 201 2) dialogam 86 no encontro do grupo:

$\bigcirc$ que eu achei interessante é que, parece que a Brenda é um pouco mais velha do que eu, eu tive uma educação diferente, mas quando a gente para mesmo para pensar, refletir em como a gente aprendeu, você vê que a sua prática não muda muito, do que você aprendeu (MERENGUE, 2011 ).

Você faz isso até mecanicamente, sem perceber, nem vai buscar outro conhecimento, porque você não sabe buscar, e a partir do momento que você começa ver o outro e que você começa ter essas reflexões, é que você vai caindo em si (BRIGADEIRO, 2011 ).

Eu penso "por que eu estou ensinando isso na matemática? Onde eu quero que ele chegue?". Eu acho que agora eu tenho mais essa convicção, eu estou ensinando isso, porque eu tenho esse objetivo. Antes, eu não tinha esse olhar, mas eu acho que também é pelo passado, a gente vai usando a experiência que vai tendo em sala de aula (SUSPIRO, 2011 ).

Após a leitura do texto de Mengali (2011), Merengue (GRUPO DE DISCUSSÂO II, 201 2) defendeu a possibilidade da transformação da prática 
estar no "parar para pensar", refletindo "no como" aprendeu. A professora disse, também, que as coisas acontecem de maneira automática, impedindo a reflexão necessária.

As narrativas possibilitam a pausa necessária para a reflexão que leva à tomada de consciência de ser professora. É uma busca de sentido nas ações, como descreve Suspiro (GRUPO DE DISCUSSÃO II, 20 1 2) ao defender a necessidade de se ter objetivo ao ensinar matemática.

Com a narrativa de vida, o sujeito toma consciência da autoformação, pois, como afirma Pineau (2010, p. 11 2), "[...] a construção e a regulação dessa historicidade pessoal são talvez as características mais importantes da autoformação, as que a fundamentam dialeticamente [...]" em uma relação espacial e social.

Consideramos importante ressaltar o quanto as professoras se identificaram com as histórias das demais colegas, quando elas foram compartilhadas no grupo. Assim, uma narrativa escrita, ao ser lida pelos pares,

[...] permite o encontro do professor-autor e professora-autora com seus pares para compartilharem experiências, saberes e acontecimentos. É nesse encontro que se dão vários acontecimentos. Que se abre um campo de possibilidades. Encontro de problematizações. Encontro de movimentos do pensamento, da reflexão, do questionamento, da ressignificação de experiências, reelaboração de outras práticas e compreensão da própria prática docente (PRADO; DAMASCENO, 2007, p. 23).

Além disso, a maneira que recebe a narrativa do outro mostra as "[...] relações sociais estáveis dos falantes [...]" (BAKHTIN, 1981, p. 147). Como pontua Bakhtin (1981, p. 147), "[...] conforme a época ou os grupos sociais, conforme o contexto apresente tal ou qual objetivo específico, vê-se dominar ora uma forma ora outra, ora uma variante ora outra".

Delory-Momberger (2008, p. 62) afirma ser a narrativa do outro "[...] um dos lugares onde experimentamos nossa própria construção biográfica; onde ela pode deslocar-se, reconfigurar-se, alargar seu horizonte; onde ela se põe à prova $[\ldots]^{\prime \prime}$, como pertencente a si.

Sobre o processo de transformação, a professora Bombom (2011), ao citar a Alaíde, sua professora modelo, declara que, como ela, problematizava a matemática e em outro momento diz "[...] a professora Alaíde fazia 
bastante perguntas e lançava vários desafios [...]", apesar de não se arriscar em participar, "[...] achava bem legal [...]" e "[...] essa prática eu ainda faço até hoje, não sei se é da maneira correta, mas eu sei que ajuda e que eu percebo que os alunos gostam [...]". Ao refletir sobre sua prática, Bombom (2011) diz: "O que eu aprendi até agora, vamos dizer, é pouco, mas até o momento foi suficiente para eu perceber a diferença de como era antes e como sou hoje. Porque antes eu não era nada, era professora, só uma professora".

Em seus primeiros anos de docência, Bombom (2011) não se sentia professora, não se reconhecia no Magistério. Passou por várias escolas e reproduziu práticas de ensino sem saber se eram boas ou não, como afirmado por ela: "[...] fiz o que tinha que fazer e nem sei se deixei alguma coisa boa ou ruim".

A formação profissional parece crescer em seu discurso e, ao narrar, toma consciência de sua própria trajetória. Para Bruner (1997, p. 11 5), "[...] conhecemos o mundo de maneiras diferentes, a partir de posicionamentos diferentes, e cada uma dessas maneiras na qual o conhecemos produz estruturas ou representações ou o fato, 'realidades' diferentes". A maneira como Bombom (2011) narra o contexto em que se tornou professora produz uma realidade. 88 Ela diz no início da entrevista, "[...] olha a palavra, eu só passei pelas escolas $[\ldots]^{\prime}$; depois, declara que pode ter ficado esquecida, "[...] eu só tinha o nome de professora $[. . .]^{\prime}$; mais adiante afirma que "[...] hoje teve muita mudança sim, porque hoje eu me sinto professora [...]"; e descreve o processo de seu desenvolvimento, "[...] eu quero transformar a criança, e ela vai conseguir, ela tem que $[. .$.$] ", sustentando-o pelo argumento de que é uma docente, "[...] sou$ professora ou eu me sinto professora, são falas completamente diferentes [...]"; até que conclui, com "[...] muita propriedade $[\ldots]$ ", que é professora, "[...] agora eu sou professora [...]".

Bombom vai modificando as crenças do ensino da matemática no momento em que vai para escola onde trabalhava na época da pesquisa. Como exposto anteriormente, "[...] agora aqui na EMEB é assim, até hoje eu estou aprendendo muito, desde o dia em que eu entrei, porque, sinceramente, aprendi com os professores, aprendi muito com a N., com você como coordenadora" (BOMBOM, 2011 ).

Cajuzinho expõe outro exemplo de como o trabalho ocasiona transformações na maneira de pensar, no caso, por meio da colaboração da 
coordenadora. Ela narra como foi mudando a sua forma de ensinar o algoritmo da subtração.

Ela falou: 'não, não, não, pode parar. Não é assim que você vai ensinar'. Ela falou assim: 'depois eu vou te ensinar como você vai ensinar. Muda a sua aula...' Num dia de H.E. [Hora de Estudo], ela me ensinou. 'Olha, você não pode subir o número e descer o número'. 'Você vai ter que emprestar do vizinho. Quem é esse vizinho? A dezena e você vai passar um? Não, você vai passar dez'. É o que eu faço hoje. Eu não continuo emprestando, agora eu faço da forma de cortar. Eu não consigo mais fazer o pauzinho em cima e o pauzinho embaixo (CAJUZINHO, 2011 ).

Merengue (201 1; grupo de discussão II, 2012) e Paçoca (2012) também relatam algumas transformações que ocorreram na vida profissional e marcaram o tempo com o ingresso no município de Jundiaí, como visto nos trechos a seguir:

A maior modificação que teve foi quando eu vim para o Município, porque a prática aqui é diferente, eu tive que rever os meus conceitos. Principalmente a matemática, tinha só o conceito mecânico, eles fazem, fazem, de maneira diferente (MERENGUE, 2011 ).

Tanto em Várzea Paulista, escola particular em Campo Limpo que eu trabalhei dois anos, eu não via essa diferença na prática, essa reflexão, essa preocupação em refletir e mudar a prática (MERENGUE, 2012. Grupo de discussão).

Mas, hoje eu vejo que poderia ser trabalhado diferente. Por exemplo, na adição com reserva, quando sobe um, quando sobem 10, eu aprendi que subia 1. Eu vim a aprender que sobe 10, depois que eu comecei a trabalhar, que eu aprendi que era 10. Na época que eu aprendi sequência numérica de forma mecânica. [...] Eu acho que foram muitos os fatores que contribuíram para que ocorressem modificações [...] a mudança para um estado maior, ter oportunidade de participar de formação continuada, as capacitações são importantes (PAÇOCA, 2012).

Todas as entrevistadas narram as transformações ocorridas ao longo dos anos que trabalham no Magistério. Falam sobre as relações com os colegas de trabalho, o preconceito ou não com relação à formação inicial, os conteúdos de matemática, a maneira de gestar a aula e as implantações de 
políticas públicas que não têm a participação dos professores em sua elaboração. Descrevem, também, as características das escolas por onde passaram e como isso influencia na profissão.

As características observadas, na escola e/ou no município onde lecionam, pronunciam uma cultura. Como afirma Ferrarotti (2010, p. 44), "o nosso sistema social encontra-se integralmente em cada um dos nossos atos, em cada um dos nossos sonhos, delírios, obras, comportamentos. E a história desse sistema está contida por inteiro na história da nossa vida individual".

Enfaticamente, Laranjinha (201 1) e Brigadeiro (2011) narram as transformações que ocorrem, até hoje, na vida profissional. Laranjinha (2011) e Brigadeiro (201 1), entre outras coisas, falam sobre o que thes encanta na profissão: o trabalho dinâmico (LARANJINHA, 2011 ) e o resultado do trabalho (LARANJINHA, 2011 ; BRIGADEIRO, 2011 ).

As vivências com os alunos no cotidiano da sala de aula e as "capacitações" oferecidas pela rede são citadas por Suspiro (2011) como responsáveis pelo desenvolvimento do trabalho do professor. Aprendizagens que ocorrem pela reflexão da relação com os alunos e com o saber do ensinar e do aprender.

Sobre o que pode ter provocado mudanças, Beijinho (2011) destaca a formação, sendo essa boa quando incomoda e gera reflexões. Laranjinha, por sua vez, considera o trabalho como fundante na constituição profissional:

Foi realmente no trabalho, na prática, nas formações do trabalho, que eu fui mudando e tendo novas concepções [...] As crianças hoje, a gente consegue trazer as crianças para um nível de discussão que eles questionam. Eles interagem juntos e a classe se movimenta, num ensino da matemática (LARANJINHA, 2011 ).

Sua fala corrobora as posições de Tardif e Raymond (2000, p. 209), quando afirmam que o "[...] trabalho modifica a identidade do trabalhador, pois o trabalho não é somente fazer alguma coisa, mas fazer alguma coisa de si mesmo, consigo mesmo". Com as professoras colaboradoras, não aconteceu diferente. Suas concepções sobre o ensinar e o aprender matemática foram sendo aprendidas, modificadas e/ou ressignificadas ao longo do tempo. Nas vozes das professoras, percebemos que isso aconteceu a partir das vivências que tiveram em suas trajetórias. 
Nestas, é possivel ver: como elas aprenderam a matemática na formação inicial, de maneira marcante, por memorização e com ênfase nos conteúdos relacionados ao sistema de numeração; como elas aprenderam a matemática na formação acadêmica, destacando a precariedade dos cursos que formam professores e a deficiência do ensino da matemática; como ensinaram no início da carreira; e como ensinam agora, tendo em vista as ressignificações de suas concepções, por meio da mediação do outro (colega de trabalho, formador, coordenador, alunos etc.). São práticas permeadas por vivências da formação que tiveram com relação à matemática e por crenças com relação ao ensino e à aprendizagem.

Em especial, percebemos que as professoras ressignificam o saber, na EMEB, ao: prepararem as aulas juntas; ouvirem os alunos, as colegas e a coordenadora; problematizarem questões relacionadas à escola; socializarem o trabalho realizado na sala; participarem de discussões sobre o ensino e a aprendizagem da matemática, dentro e fora da escola; terem a cumplicidade da coordenadora. Somam-se a isso os encontros para a discussão em grupo, momentos que puderam refletir sobre suas trajetórias. Acontecimentos vividos que, ao serem narrados, fazem com que tomem consciência do distanciamento dos conhecimentos aprendidos na formação que tiveram. Sobre esse distanciamento, Tardif e Raymond assim se posicionam:

[...] o saber profissional comporta também uma dimensão crítica que se manifesta por meio de um distanciamento em relação aos conhecimentos adquiridos anteriormente, especialmente durante a formação universitária. Outros distanciamentos críticos ocorrem também em relação aos instrumentos de trabalho (programas, livros didáticos, diretrizes, regras do estabelecimento etc.l, que o professor adapta pouco a pouco às suas necessidades. Essa dimensão crítica parece desempenhar um papel importante na busca da autonomia profissional, pois, graças a ela, como disse um professor entrevistado, "o professor não se sente mais observado e julgado, mas torna-se aquele que observa e que julga". Para entender as transformações e os objetos dessa dimensão crítica dos saberes experienciais, devemos levar em consideração o momento da carreira no qual ela ocorre (TARDIF; RAYMOND, 2000, p. 233).

A reflexão sobre as vivências e os saberes adquiridos é capaz de levar a ressignificações dos sentidos da profissão, da tomada de consciência 
da sua identidade profissional: quem fui e quem sou atualmente, quais os acontecimentos que fizeram com que eu me transformasse (ou não).

\section{A produção de novos sentidos para a profissão e a (auto) formação}

As colaboradoras, durante a pesquisa, pontuam momentos importantes que dizem respeito aos modos de ensinar matemática e como autointerpretam este trajeto. Trajetos esses que também são considerados momentos de formação (DOMINICÉ, 2010).

Nas narrativas, identificamos a experiência de formação das professoras, pois a abordagem biográfica tem como estratégia permitir ao sujeito "[...] torna-se ator do seu processo de formação, por meio da apropriação retrospectiva do seu percurso de vida" (NÓVOA, 2010, p. 168). $\bigcirc$ trabalho realizado ao longo da carreira, com as demais colegas nessa escola, faz com que, agora, elas tomem consciência do que seja ensinar matemática.

Ao pensar a educação a partir da "experiência/ sentido", Larrosa (2002, p. 20-21) explora a ideia do significado das palavras, essas "[...]

92 produzem sentidos, criam realidades e, às vezes funcionam como potentes mecanismos de subjetivação." $\bigcirc$ autor também afirma que agimos sobre a palavra e ela age sobre nós, que pensamos com as palavras e "a partir de nossas palavras".

A partir desse pressuposto, podemos apontar que nossas personagens, em seus discursos, ao dar sentido a quem elas são e ao que thes aconteceu (LARROSA, 2002), desnudam sua identidade narrativa.

Larrosa (2002, p. 25), ao tecer o significado de experiência, pontua: "[...] a experiência é o que nos passa, o que nos acontece, o que nos toca". $\bigcirc$ autor observa, entre outros sentidos possíveis, que a capacidade de formação é um componente fundamental da experiência e que:

[...] se a experiência é o que nos acontece e se o saber da experiência tem a ver com a elaboração do sentido ou do sem-sentido do que nos acontece, trata-se de um saber finito, ligado à existência de um indivíduo ou de uma comunidade humana particular; ou, de um modo ainda mais explícito, trata-se de um saber que revela ao homem concreto e singular, entendido individual ou coletivamente, o sentido ou o sem-sentido e sua própria existência, de sua própria 
finitude. Por isso, o saber da experiência é um saber particular, subjetivo, relativo, contingente, pessoal. [...] A experiência e o saber que dela deriva são o que nos permite apropriar-nos de nossa própria vida (LARROSA, 2002, p. 27).

Podemos afirmar, ainda, que as vivências que fazem a diferença na vida das professoras constituem uma experiência formadora. Merengue (2011) conta sobre a vivência como professora e intensifica seu percurso profissional ao exemplificar uma forma de atuação docente que permitiu modificar o sentido do que seja ensinar matemática, uma vez que não tinha consciência de que o ensino pautado em técnicas e de forma mecânica não trazia para a criança a aproximação de conceitos e a apropriação de conteúdos de forma significativa. Enaltece o que Freire (1996) afirmava sobre a importância do professor que, ao ensinar, também aprende sobre o conteúdo.

Conforme eu vou aprendendo, eu vou conseguindo ensinar melhor. E vai melhorando. Porque a minha primeira experiência em ensinar foi o que eu lembrava, a forma mecânica. Duas vezes três é seis, porque duas vezes o número três, até eles entenderam a forma de simplificar a adição e para a gente entender isso, eu tenho que aprender, para depois ensinar. Conforme eu fui aprendendo, fui melhorando, mas eu voltei e olhei para trás para ver como eu tinha aprendido, e 'meu Deus como eu errei'. Mas era o que eu tinha aprendido e o que eu sabia também, não adianta. A gente faz o melhor que pode com o que se tem (MERENGUE, 2011 ).

excerto de fala de Merengue nos faz pensar, novamente, na formação contínua. No percurso profissional e nas vivências com os alunos, com os colegas, com os formadores, com a direção, com a coordenação, com os formadores externos, o professor vai modificando suas concepções sobre o ensinar e o aprender e assim (re)constrói o seu saber. Merengue (201 1), ao se referir à intencionalidade que envolve o ato de ensinar e de aprender, ainda afirma:

[...] alguns alunos têm um pouco mais de dificuldade, eu tenho que me sentar ao lado e mostrar como se faz, não adianta só falar da forma que está no livro. Logo, acaba saindo um pouco do livro, da orientação deles, mas para adaptar à necessidade do aluno. Porque o objetivo é que o aluno aprenda (MERENGUE, 2011 ). 
Esse é um compromisso profissional que vai além do cumprimento burocrático de um material didático, prevalecendo o compromisso ético do professor com relação à aprendizagem do aluno.

Brigadeiro, por sua vez, narra a importância do grupo de professores:

Essa troca de olhar com o outro, muitas vezes eu perguntava para a Cajuzinho: 'como você fez isso? Como você pensa assim? Como você fez assim?' A Cajuzinho pergunta para mim: 'e você por que você fez assim? Mas a gente fez o ano passado e não deu certo, vamos fazer desse jeito?' A Beijinho quando ia lá no MENT [Projeto desenvolvido na rede], a gente troca também. A gente diz: 'fala você porque eu gosto de ouvir como você fala'. Você fala de uma forma diferente, então, isso é legal para mim, eu ouvir o outro e aprender com o outro também (BRIGADEIRO, 2012. Grupo de discussão).

Dominicé (2010, p. 95) afirma que a formação depende do que o sujeito faz com o que os "[...] outros quiseram, ou não quiseram, fazer dele". Ele argumenta: "[...] numa palavra, a formação corresponde a um processo global de autonomização, no decurso do qual a forma que damos à nossa 94 vida se assemelha - se é preciso utilizar um conceito - a o que alguns chamam de identidade" (DOMINICÉ, 2010, p. 95).

Essa formação do "eu" é chamada por Pineau (2010) de autoformação. $\bigcirc$ autor explica:

Nesta problemática, concordamos com Dumazedier [...] a autoformação coletiva ou individual de uma pessoa supõe uma auto liberação dos determinantes cegos, fonte de estereótipos, de ideias feitas e de preconceitos, produzidos pela estrutura social (PINEAU, 2010, p. 99, grifos do autor).

Pineau afirma, ainda, que autoformação, principalmente para os mais socialmente dominados, é sofrível, além de ser uma questão de sobrevivência.

Mas, ao compartilhar a ideia de que ninguém forma ninguém, o próprio sujeito que se forma (DOMINICÉ, 2010), precisa pensar em estratégias de autoformação. Concordamos com a tese de Dominicé (2010) sobre a formação contínua por meio das narrativas. $\bigcirc$ lugar - no caso deste trabalho, a escola - se torna um contexto educativo propício à reflexão que permite avançar as hipóteses. Apontamos, nesse caso, a importância do apoio da 
universidade, com suas pesquisas e com seus agentes, para que a reflexão não fique no senso comum e que avance com criticidade. Ao destacarmos as discussões realizadas no cotidiano escolar, não negamos a contribuição de outros espaços de formação.

Ressaltamos, também, que não se trata de qualquer escola, com qualquer grupo de profissionais. É necessário que haja essa intencionalidade formativa no coletivo dos professores. Nesse sentido, ao apresentarmos a EMEB anteriormente neste texto, nossa intenção era evidenciar como naquela escola existe um contexto propício à formação contínua dos professores, construída coletivamente com apoio da equipe gestora.

\section{Algumas amarras...}

A reflexão com as professoras sobre os processos de formação evidencia a identidade profissional construída e os saberes profissionais que elas foram se apropriando a partir de suas práticas de ensinar e de aprender a ensinar matemática. Saberes que influenciam o que e o como se ensina. Nas narrativas pudemos identificar saberes disciplinares, pedagógicos do conteúdo, curriculares, profissionais e experienciais, sendo que esse último perpassa todos os outros e os modela (TARDIF, 2002).

A identidade pessoal, que se forma da relação com a identidade social, é percebida a partir da reflexão das trajetórias de formação e profissional dessas professoras. No coletivo dos professores, elas foram se constituindo, mas sem perder suas singularidades.

O grupo de discussão-reflexão é um espaço mediador para o compartilhamento das trajetórias de vida. Ao articular o individual e o coletivo da profissão, os seus membros, em sentido de colaboração e de maneira reflexiva, criam condições de formação contínua. Podemos afirmar que a formação alcançada tem uma ação sobre o campo profissional e busca desenvolver a capacidade de agir dos trabalhadores sobre eles mesmos e sobre o campo profissional.

Para este trabalho, a atividade formadora das histórias de vida, pela reconstituição da própria história de formação e discussão no grupo, permitiu que as professoras tivessem "[...] acesso à própria capacidade de mudança" 
(DELORY-MOMBERGER, 2008a, p. 32), capacidade também conhecida como autoformação.

Isso gera a necessidade de se pensar no coletivo:

Vigotski apresenta a ideia de que o social não é simplesmente uma coleção de indivíduos, não é simplesmente o encontro de pessoas; o social está em nós, no corpo, no pensamento; de certa maneira, é um recurso muito importante para o desenvolvimento da subjetividade. Nesse sentido, o coletivo não é uma coleção, é o contrário da coleção. O coletivo, nesse sentido, é entendido como recurso para o desenvolvimento individual (CLOT, 2006, p. 102).

Acreditamos que a visibilidade do processo de formação vivido pelas professoras colaboradoras só foi possível no momento em que paramos para discutir a nossa formação no grupo promovido pela pesquisa. Nesse momento, ao ouvir as histórias das colegas, cada uma foi produzindo sentidos para a sua própria história de formação, seus primeiros anos de docência, as práticas que foram reproduzidas, os espaços de formação frequentados e as aprendizagens ocorridas. Evidenciamos, também, que todo esse movimento foi ampliado 96 e consolidado pelos momentos de discussão coletiva na escola, nas horas de estudo. As formações ofertadas pela rede eram analisadas e discutidas no coletivo das professoras, o que possibilitava um processo de ressignificação das práticas.

Os grupos de discussão ampliaram esse movimento de reflexão, oportunizando que elas tomassem consciência das vivências pelas quais passaram e das experiências que deixaram marcas. Compreendemos que o sujeito pode "[...] transformar a experiência vivida de um objeto em objeto de uma nova experiência vivida [...]" (CLOT, 2010, p. 202), a partir da tomada de consciência de sua trajetória.

A análise aqui realizada possibilita-nos pensar em como o trabalho docente é central ao processo identitário dessas professoras e como as narrativas que elas constroem sobre ele foram contributivas para a ressignificação das práticas de ensinar matemática. Assim, elas se tornaram autoras do próprio processo de formação e, nesse sentido, as narrativas contribuem para a autoformação. 


\section{Referências}

BAKHTIN, Mikhail (Volochinov). Marxismo e filosofia da linguagem. Tradução de Michel Lahud e Yara Frateschi Vieira. 2. ed. São Paulo: Hucitec, 1981.

BEIJINHO. Entrevista oral. Jundiaí (São Paulo), 20 out. 2011.

BERTAUX, Daniel. Narrativas de vida: a pesquisa e seus métodos. Tradução de Zuleide Alves Cardoso Cavalcante e Denise Maria Gurgel Lavallée. Natal: EDUFRN; São Paulo: Paulus, 2010.

BOMBOM. Entrevista oral. Jundiaí (São Paulo), 26 out. 2011.

BRIGADEIRO. Entrevista oral. Jundiaí (São Paulo), 30 ago. 2011.

BRUNER, Jerome. Realidade mental, mundos possíveis. Tradução Marcos A. G. Domingues. Porto Alegre: Artmed, 1997.

CAJUZINHO. Entrevista oral. Jundiaí (São Paulo), 20 out. 2011.

CLOT, Yves. Entrevista: Yves Clot. Cadernos de Psicologia Social do Trabalho, São Paulo, v. 9, n. 2, p. 99-107, dez. 2006.

CLOT, Yves. Trabalho e poder de agir. Tradução Guilherme João de Freitas Teixeira e Marlene Machado Zica Vianna. Belo Horizonte: Fabrefactum, 2010.

CUNHA, Renata Barrichelo; FERNANDES, Carla Helena; MOTA, Ednaceli Abreu Damasceno; NOGUEIRA, Eliane Greice Davanço. Professora: os elementos de uma identidade em construção. Pro-Posições, Campinas, v. 18, n. 1, p. 153-167, jan./abr. 2007.

DELORY-MOMBERGER, Christiane. Biografia e educação: figuras do indivíduo-projeto. Tradução Maria Conceição Passeggi, João Gomes da Silva Neto e Luis Passeggi. Natal: EDUFRN; São Paulo: Paulus, 2008.

DELORY-MOMBERGER, Christiane. Introdução: Pesquisa biográficas em Educação: Orientações e territórios. In: SOUZA, Elizeu Clementino; PASSEGGI, Maria Conceição; ABRAHÃO, Maria Helena Menna Barreto (Org.). Pesquisa (auto)biográfica e práticas de formação. Natal: EDUFRN; São Paulo: Paulus, 2008a.

DOMINICÉ, Pierre. $\bigcirc$ processo de formação e alguns dos seus componentes relacionais. In: NÓVOA, António; FINGER, Matthias (Org.). O método (auto)biográfico e a formação. Natal: EDUFRN; São Paulo: Paulus, 2010. 
O que a vida thes ensinou. In: NÓVOA, António; FINGER, Matthias (Org.). 0 método (auto)biográfico e a formação. Natal: EDUFRN; São Paulo: Paulus, 2010 a.

FERRAROTTI, Franco. Sobre a autonomia do método biográfico. In: NÓVOA, António; FINGER, Matthias (Org.). O método (auto|biográfico e a formação. Natal: EDUFRN; São Paulo: Paulus, 2010.

FREIRE, Paulo. Pedagogia da autonomia: saberes necessários à prática educativa. Rio de Janeiro: Paz e Terra, 1996.

JOSSO, Marie-Christine. Os relatos de histórias de vida como desvelamento dos desafios existenciais da formação e do conhecimento: destinos sócio-culturais e projetos de vida programados na invenção de si. In: SOUZA, Elizeu Clementino; ABRAHÃO, Maria Helena Menna Barreto (Org.). Tempos e narrativas e ficções: a invenção de si. Porło Alegre: EDIPUCRS, 2006.

JOVCHELOVITCH, Sandra; BAUER, Martin W. Entrevista narrativa. In: BAUER, Martin W; GASKELL, George (Org.). Pesquisa qualitativa com texto, imagem e som: um manual prótico. 4. ed. Petrópolis: Vozes, 2005.

LARANIINHA, Entrevista oral. Jundiaí (São Paulo), 21 out. 2011.

98 LARROSA, Jorge. Notas sobre a experiência e o saber de experiência. Revista Brasileira de Educação, Rio de Janeiro, n. 19, p. 20-28, jan./abr. 2002.

MACHADO, Anna Rachel. Por uma visão ampliada do trabalho do professor. In: GUIMARÃES, Ana Maria de Mattos; MACHADO, Anna Raquel. O interacionismo sociodiscursivo: questões epistemológicas e metodológicas. Campinas: Mercado de Letras, 2007.

MARCELO, Carlos. A identidade docente: constantes desafios. Tradução de Cristina Antunes. Formação Docente, Belo Horizonte, v. 1, p. 109-131, ago./dez. 2009.

MERENGUE. Entrevista oral. Jundiaí (São Paulo), 1 set. 2011.

MENGALl, Brenda Leme da Silva. A cultura da sala de aula numa perspectiva de resolução de problemas: o desafio de ensinar matemática numa sala multisseriada. 2011. $218 f$. Dissertação (Mestrado em Educação) - Programa de Pós-Graduação em Educação, Universidade São Francisco, Itatiba, 2011.

MOITA, Maria da Conceição. Percursos de formação e de transformação. In: NÓVOA, António. Vidas de professores. Porto: Porto Editora, 1995. 
NACARATO, Adair Mendes; PASSEGGI, Maria da Conceição. Olhar para si e superar marcas deixadas pela matemática escolar: reflexões de uma futura professora sobre seu percurso de formação. In: OLINDA, Ercília Maria Braga de. Artes de sentir: trajetórias de vida e formação. Fortaleza: Edições EFC, 2012.

NÓVOA, António. A formação tem que passar por aqui: as histórias de vida no Projeto Prosalus. In: NÓVOA, António; FINGER, Matthias (Org.). O método (auto)biográfico e a formação. Natal: EDUFRN; São Paulo: Paulus, 2010.

PAÇOCA. Entrevista oral. Jundiaí (São Paulo), 22 mar. 2012.

PINEAU, Gaston. A auto-formação no decurso da vida: entre a hetero e a ecoformação. In: NÓVOA, António; FINGER, Matthias (Org.). O método (auto)biográfico e a formação. Natal: EDUFRN; São Paulo: Paulus, 2010.

PRADO, Guilherme do Val Toledo; ROSA, Maria Inês Petrucci dos Santos; SADALLA, Ana Maria Falcão de Aragão; GERALDI, Corinta Maria Grisolia. GEPEC: A educação continuada ao desenvolvimento pessoal e profissional em uma perspectiva narrativa. In. SOUZA, Elizeu Clementino; PASSEGGI, Maria da Conceição; ABRAHÃO, Maria Helena Menna Barreto (Org.). Pesquisa (auto|biográfica e práticas de formação. Natal: EDUFRN; São Paulo: Paulus, 2008.

PRADO, Guilherme do Val Toledo; DAMASCENO, Ednaceli A. Saberes docentes: narrativas em destaque. In: VARANI, Adriana; FERREIRA, Cláudia Roberta; PRADO, Guilherme do Val Toledo (Orgs.). Narrativas docentes: trajetórias de trabalhos pedagógicos. Campinas: Mercado de Letras, 2007, p. 15-27.

SOUZA, Elizeu Clementino. Pesquisa narrativa e escrita (auto) biográfica: interfaces metodológicas e formativas. In: SOUZA, Elizeu Clementino; ABRAHÃO, Maria Helena Menna Barreto (Org.). Tempos e narrativas e ficções: a invenção de si. Porto Alegre: EDIPUCRS, 2006.

SUSPIRO. Entrevista oral. Jundiaí (São Paulo), 30 set. 2011.

TARDIF, Maurice. Saberes docentes e formação profissional. Petrópolis: Vozes, 2002.

TARDIF, Maurice; LESSARD, Claude. O trabalho docente: elementos para uma teoria da docência como profissão de interações humanas. Petrópolis: Vozes, 2005.

TARDIF, Maurice; RAYMOND, Danielle. Saberes, tempo e aprendizagem do trabalho no magistério. Educação \& Sociedade, Campinas, v. 21 , n. 73, p. 209-244, dez. 2000. 
WELLER, Wivian. Grupos de discussão na pesquisa com adolescentes e jovens: aportes teórico-metodológicos e análise de uma experiência com o método. Educação e Pesquisa, São Paulo, v. 32, n. 2, p. 241-260, maio/ago. 2006.

Ms. Marjorie Samira Ferreira Bolognani Universidade São Francisco | Bragança Paulista Doutoranda do Programa de Pós-Graduação em Educação Grupo de Pesquisa em Histórias de Formação de Professores que Ensinam Matemática | HIFOPEM E-mail | marioneł@gmail.com

Profa. Dra. Adair Mendes Nacarato Universidade São Francisco | Bragança Paulista Docente do Programa de Pós-Graduação em Educação Líder do Grupo de Pesquisa em Histórias de Formação de Professores que Ensinam Matemática | HIFOPEM E-mail | adamn@terra.com.br

Recebido 14 set. 2014 Aceito 8 nov. 2014 